Archived version from NCDOCKS Institutional Repository http://libres.uncg.edu/ir/asu/

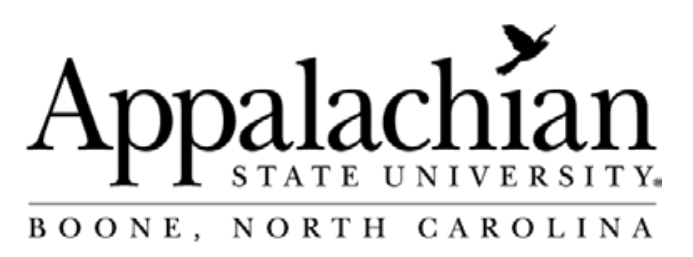

Matthew B. Robinson (1999) LIFESTYLES, ROUTINE ACTIVITIES, AND

RESIDENTIAL BURGLARY

VICTIMIZATION, Journal of Crime and

Justice, 22:1, 27-56, DOI:

10.1080/0735648X.1999.9721081 Published online: 10 Jan 2012. 


\title{
LIFESTYLES, ROUTINE ACTIVITIES, AND RESIDENTIAL BURGLARY VICTIMIZATION•
}

\author{
Matthew B. Robinson \\ Appalachian State University
}

\begin{abstract}
This paper reports findings from an exploratory, place specific study of the relationship between victims' lifestyles, routine activities, and residential burglary victimization. A telephone survey differentiated people with various lifestyles in terms of daily obligatory and discretionary activities. These differential lifestyles were related to variations in routine activities (i.e., pedestrian and automotive traffic) on street segments around residential areas. In a pooled cross-sectional design, street segments with higher volumes of routine activities between 1992-1996 had significantly lower burglary rates over this time period, as did street blocks with irregular periods of routine activities in 1997. Implications are discussed for the lifestyle I exposure and routine activity theories and for the movement in criminology away from explaining why individual offenders commit crimes, toward explaining why crimes happen at particular places atparticular times and not others.
\end{abstract}




\section{INTRODUCTION}

All crimes are events that occur in space and time (Chapin, 1974; Felson, 1983); all crimes have spatial and temporal elements (Robinson, 1997b). Legal activities of people in space and time "set the stage for spatial and temporal patterns of ' illegal activities (Felson. 1983:665). In other words, "crime derives from many of the good aspects of society" (Felson, 1994:21). "Society provides temptations to commit crimes" (Felson, 1994:22, 42), as well as simple opportunities for crimes to successfully occur. Increases in crime may also depend on a lack of "controls to prevent people from following these temptations," which society also provides. Therefore, the type and amount of crime a society has is organized by routine legitimate activities of everyday life. For example, what victims do, and where and when they do it -- helps determine the where and when of crime.

Opportunity theories, most notably routine activity theory (Cohen and Felson, 1979), and lifestyle/exposure theory (Hindelang, Gottfredson, and Garofalo, 1978), have taught us this lesson. The result has been that criminologists are beginning to seriously examine spatial and temporal elements of individual crime types, housed under the notion of the "place of crime $^{11}$ (Eck and Weisburd, 1995). To increase our understanding of criminality -- i.e., why individuals commit crimes -- we must first direct our efforts at understanding actual criminal events -- i.e., why some places and victims become targets for crime more than others (Weisburd, 1997).

This paper reports findings from an exploratory, place-specific study of the relationship between victims' lifestyles, routine activities, and burglary victimization. The author discusses the implications of his findings for lifestyle I exposure and routine activities theories. The study strives to encourage the movement in criminology which is shifting our focus away from focusing on offenders and explaining why individuals commit crimes, toward accounting for why crimes happen at particular places at particular times and not others.

\section{VICTIMS AND CRIME}

Historically, criminologists have ignored the role of places and targets in criminal events; focusing instead on offenders (Eck and Weisburd, 1995; Weisburd, 1997). This omission has produced a basic lack of understanding of criminal events (Garofalo, 1987). When criminologists ignore the place and target of crime and focus on the offender, the role that 
victims play in criminal events is neglected (Fattah, 1993). Logically, no crime can occur without a target (i.e., the victim or the victim's property).

Mostly because of the development and testing of opportunity theories of criminal events such as lifestyle $I$ exposure theory (Hindelang, Gottfredson, and Garofalo, 1978) and routine activity theory (Cohen and Felson, 1979), criminologists have recently recognized the relationship between the lifestyles of potential victims and criminal events. Criminologists have recognized that whether criminal events occur, as well as where they occur in space and when they occur in time, is partially contingent on where and when routine activities of potential victims occur (Robinson, 1997b).

\section{Lifestyle/Exposure Theory}

The "lifestyle/exposure theory" was developed by Hindelang, Gottfredson, and Garofalo (1978:243; e.g., see Goldstein, 1994; Maxfield, 1987:275; Miethe, Stafford, and Long, 1987:184). This model of criminal events links victimization risks to the daily activities of specific individuals (Goldstein, 1994:54; Kennedy and Forde, 1990:208).

Lifestyles are patterned, regular, recurrent, prevalent, or "routine activities" (Robinson, 1 997b; also see Cohen and Felson, 1979; Felson, 1994; Hindelang, Gottfredson, and Garofalo, 1978:241; Garofalo, 1987:24, 39). Lifestyles consist of the activities that people engage in on a daily basis, including both obligatory and discretionary activities. LeBeau and Coulson (1996:3; also see LeBeau and Corcoran, 1990) assert that:

The former are activities that must be undertaken while the latter because they are pursued by choice are called discretionary. 'An activity is discretionary if there is a greater chance of choice than constraint, and obligatory if there is a greater degree of constraint than choice" (Chapin, 1974:38). Both activities have a duration, position in time, a place in a sequence of events, and a fixed location or path in space (Chapin, 1974:37).

Kennedy and Forde (1990:208) summarized the lifestyle/exposure model as "lifestyle, encompassing differences in age, sex, marital status, family income, and race, influences daily routines and vulnerability to criminal victimization, resulting in the fact that "Victimization is not evenly distributed randomly across space and time -- there are high-risk locations and high-risk time periods" (Garofalo, 1987:26). "Lifestyle patterns 
influence (a) the amount of exposure to places and times with varying risks of victimization, and (b) the prevalence of associations with others who are more or less likely to commit crimes."

A similar theoretical model developed by Kennedy and Forde (1990: 209, 211) suggested that background characteristics and daily activities affect time spent in risky lifestyles which lead to dangerous results (i.e., criminal victimization). In their words, "demographic and lifestyle variables ... can be interpreted as contributing to more or less 'time spent in risky activities' and indirectly contributing to 'dangerous results"' (Kennedy and Forde, 1990:209).

Numerous studies have shown relationships between daily activities of individuals and their likelihood of criminal victimization (Riley, 1987:340). In other words, what people do and how they behave places them at either more or less risk of criminal victimization (Maxfield, 1987; Miethe, Stafford, and Long, 1987; Sampson and Wooldredge, 1987).

According to Sampson and Wooldredge (1987:372): "An active lifestyle . . . appears to influence victimization risk by increasing exposure of persons and homes to potential offenders while guardianship is low." Yet, an active lifestyle may not necessarily increase one's risk of criminal victimization. For example, if there is a great deal of activity by residents, neighbors, or passers by around a residence, then this activity may serve to decrease the likelihood that a property offender will victimize a residence. In fact, many property offenders are non-confrontational and want to avoid being seen by residents, neighbors, or passers by (Cromwell, Olson, and Avary, 1991; Tunnell, 1994; Wright and Decker, 1994).

Whether an active lifestyle leads to higher or lower risks for criminal victimization may depend on several factors. It might depend on the nature of one's activities -- i.e., whether they are patterned and predictable to offenders, or sporadic and less predictable. This issue has not been settled by academic research, although the majority of lifestyle research suggests that active lifestyles increase risks for criminal victimization (Robinson, 1997b). Part of why there is some uncertainty about this issue is because when relationships between lifestyles and crime are studied, dependent variables typically consist of some composite measure of crime (see Robinson, l 997b; Thompson and Fisher, 1996). Whether active lifestyles lead to higher or lower risks for crime might depend on the specific type of crime that is being studied. Since composite measures of crime have been utilized by researchers rather than distinct measures of individual crime types (Bennett, 1991; Maxfield, 1987; Thompson and Fisher, 1996), it is nearly impossible to differentiate the effects of peoples' lifestyles on different types of criminal victimization. This is problematic, because lifestyle/exposure theory is "crime specific" 
(Bennett, 1991:158; Thompson and Fisher, 1996). For example, crimes such as burglary and theft may create different opportunities for offenders:

For a burglary to occur, an offender has to break and enter a home to get the desired goods. An offender who commits a larceny, on the other hand, may ride off with a bicycle left out on the lawn or steal something from the porch of a home. These examples demonstrate that the opportunity structure for burglary and larceny are different and therefore the two crimes must be examined separately in research (Thompson and Fisher, 1996:52; also see Gottfredson, 1984; Maxfield, 1987; Sampson and Wooldredge, 1987).

Research examining the relationship between lifestyles and crime should avoid pooling or aggregating crime types, because examining the effects of lifestyles on composite measures of crime leads to inconsistent findings (Thompson and Fisher, 1996:53).

\section{Routine Activity Theory}

According to routine act1v1ty theory, crime results from the convergence of three elements in time and space: a presence of likely or motivated offenders; a presence of suitable targets; and an absence of capable guardians to prevent the criminal act (Cohen and Felson, 1979:588; Cohen, Felson, and Land, 1980:97; Felson, 1983:666, 1987, 1994, 1995; Kennedy and Baron, 1993; Kennedy and Forde, 1990; Massey, Krohn, and Bonati, 1989; Maxfield, 1987; Miethe, Stafford, and Long, 1987; Roncek and Maier, 1991; Sherman, 1995:38; Sherman, Gartin, and Buerger, 1989).

A "likely offender" includes anyone with an inclination to commit a crime (Felson, 1983:666). A "suitable target" includes any person or thing that may evoke criminal inclinations, which would include the actual value of the target and the monetary and symbolic desirability of it for offenders, the visibility to offenders or their informants, the access to it, the ease of escape from the site, as well as the portability or mobility of objects sought by offenders (Felson, 1983:666). A "guardian" is a person who can protect a target (Eck and Weisburd, 1995:5), including friends and formal authorities such as police and security personnel, "intimate handlers" such as parents, teachers, coaches, friends, employers, and "place managers" such as janitors, and apartment managers (e.g., see Eck, 1994; Eck and Weisburd, 1995:5, 6, 55; Felson, 1986, 1995:21). Eck (1994) wrote that the potential target was supervised by the guardian, the potential offender by the handler, and the potential place of crime by the place manager. The 
guardian, handler, and manager must be absent or ineffective from the potential target, the potential handler, and the place, respectively, for crime to occur (Eck and Weisburd, 1995:21).

An "absence of capable guardians" can be produced by average citizens going about their daily life (Felson, 1983:666). In fact, the most important guardians are ordinary citizens going about their daily routines (Felson, 1994:31). Clarke and Felson (1993:3) wrote that the "typical guardian" is not a policeman or security guard in most cases, but that the most likely persons to prevent crime were "neighbors, friends, relatives, bystanders, or the owner of the property." This means that routine activities of potential victims not only facilitate criminal victimization, but they may also prevent it.

'Routine activities' include "any recurrent and prevalent activities which provide for basic population and individual needs, whatever their biological or cultural origins . . . including formalized work, leisure, social interaction, learning . . . which occur at home, in jobs away from home, and in other activities away from home" (Cohen and Felson, 1979:593). Routine activities are the means people use to satisfy their needs, which are specific to their lifestyles.

In routine activity theory, "the timing of work, schooling, and leisure" is thought to be "of central importance for explaining crime rates" (Cohen and Felson, 1979:591). Additionally, the "dispersion of activities away from households and families increases the opportunity for crime and thus generates higher crime rates" (Cohen and Felson, 1979:588, 593; also see Garofalo, 1987:26), since "greater absence from the home decreases the presence of guardians of household property, making households more suitable targets" (Garofalo, 1987:26-27).

Cohen and Felson wrote that "we expect routine activ1t1es performed within or near the home and among family or other primary groups to entail lower risk of criminal victimization because they enhance guardianship capabilities" (Cohen and Felson, 1979:594). That is, since higher levels of guardianship increases the likelihood that offenders will be seen, the risk for criminal victimization is reduced. Felson (1983:667) discussed how a "far greater risk of both personal and property victimization was incurred by engaging in activities away from family and household settings" since the "organization of daily life in the modem metropolis assembles or disperses people for work, school, shopping, and leisure in fashion that invites crime" (Felson, 1987:125-126). In fact, "Any social trends that draw people away from home" are important for crime rate analysis (Felson, 1987:667).

The factors leading to increased risks in Cohen and Felson's (1979) original routine activity model were increases in working women, single 

adults, college students, and others engaging in nonfamily and nonhousehold activities, which made it more likely that likely offenders would come into direct contact with suitable targets in the absence of capable guardians against crime (Felson, 1983:668). Cohen and Felson (1979:598) found that increasing crime rates corresponded to time spent outside of the home and rates of out of town travel. For example, daytime burglaries increased over time along with time spent outside of home during the day (Cohen and Felson, 1979:600).

Other research supports the expectation that the dispersion of activities away from households and families is related to the crime rate. For example, Miethe, Stafford, and Long (1987: 192) found that persons with low daytime and nighttime activity outside of the home had the lowest risk of property victimization, and people who found themselves away from the home due to daytime and nighttime activity had the highest risks for crime victimization. Likewise, Felson and Gottfredson (1984:709) showed that a decline in the amount of time adolescents spent in family and households with a parent nearby, meant less potential for informal social control and thus, more crime over time.

Overall, the findings from routine activity research indicate that the risk for criminal victimization varies "among the circumstances and locations in which people place themselves and their property" (Cohen and Felson, 1979:595). For example, Cohen and Felson (1979:596) claimed that victimization rates varied inversely with age and were lower for people with "less active" statuses such as keeping house, being unable to work, being retired, etc. However, Cohen and Felson did not actually measure activity levels associated with each status. In fact, lifestyles or routine activities of potential victims are typically inferred from demographic variables; they are rarely directly measured (Akers, 1994; Kennedy and Forde, 1990; Maxfield, 1987; Miethe, Stafford, and Long, 1987; Moriarty and Williams, 1996; Sampson and Wooldredge, 1987).

\section{Differences Between Lifestyle/Exposure and Routine Activity Theories}

Both lifestyle/exposure and routine activity theories can be considered as subsets of a more general opportunity model (Cohen, Kluegel, and Land, 1981; Sampson and Wooldredge, 1987). Garofalo (1987:27) pointed out the basic differences between the two approaches, noting that they "relate to how they were explicated by their authors rather than to difference in substance." For example, Cohen and Felson (1979) utilized aggregate measures of routine activities and linked them to changes 
in crime rates over time, while Hindelang, Gottfredson, and Garofalo ( 1978) related differences in lifestyles of population segments at one point in time to differential victimization rates.

\section{Summary}

Despite the large amount of research using multiple datasets and measures (Thompson and Fisher, 1996) and the common sense understanding about criminal events which underlies it, the precise relationship between lifestyles and routine activities of potential victims and victimization from various crime types is still unclear, because:

* Composite measures of crime have typically been utilized by researchers rather than distinct measures of individual crime types (Bennett, 1991; Maxfield, 1987; Thompson and Fisher, 1996; Robinson, 1997b), making it nearly impossible to differentiate the effects of peoples' lifestyles on different types of criminal victimization; and

* Lifestyles or routine activities of potential victims are typically inferred from demographic variables; they are rarely directly measured (Maxfield, 1987), except through self-report techniques (e.g., see Abercrombie et al., 1974; Clark 1988; Cohen and Cantor, 1981; Cohen and Felson, 1979; Corrado et al., 1980; Felson and Gottfredson, 1984; Godschalk and Godschalk, 1966; Hough, 1987; Illinois Reminiscence Survey, 1979; Kennedy and Forde, 1990; Lasley and Rosenbaum, 1988; Massey, Krohn, and Bonati, 1989; Maxfield, 1987; Miethe, Stafford, and Long, 1987; Riley, 1987; Robinson, 1995; Sampson and Wooldredge, 1987; Smith, 1982), meaning many studies are plagued by circular reasoning (Hough, 1987; Kennedy and Forde, 1990; Miethe, Stafford, and Long, 1987; Sampson and Wooldredge, 1987).

Results from studies plagued by these problems have led to a lack of basic understanding about how people's lifestyles and routine activities affect their risks for various types of criminal victimization. Therefore, the author conducted an exploratory, place-specific study to focus on the context of crime, and to overcome the main weaknesses of previous studies discussed above. The study examines the relationship between lifestyles and routine activities of potential victims and criminal victimization for an individual crime type (residential burglary), and actually measures lifestyles and routine activities of potential victims rather than inferring them from people's statuses. 


\section{METHODS}

\section{The Area of Study}

The area of focus in this study was Zone 7 of the Tallahassee, Florida Police Department (TPD) jurisdiction. Zone 7 is an appropriate area for this study for several reasons. First, previous studies (Robinson, 1994, 1995, 1996, 1997a, 1997b; Robinson and Robinson, 1997) have focused on this area. The previous studies, which primarily examined student apartment burglary, were conducted in Zone 7 because of its high proportion of students and student apartment complexes. These previous studies showed that rates of burglary were four to five times lower for student apartment complexes than for all other types of residences in the same area (Robinson, 1997b). This study focuses on Zone 7 in order to discover correlates of this rate differential and to increase knowledge regarding specific places within this area. Second, Zone 7 contains a variety of lifestyles; it is characterized by high amounts of both students and non-students, including state employees, and retired and unemployed citizens. A study probing lifestyle variations must be conducted in an area in which lifestyles actually vary. Third, Zone 7 was selected for study due its high rates of reported crime. This assured having adequate samples of reported residential burglaries to work with. Recent statistics from the Tallahassee Police Department (TPD) suggest that Zone 7 has the highest rate of residential burglary in the city. Finally, due to the time involved in providing the data for this study, only residential burglary data between 1992-1996 from one police zone could be obtained from TPD.

\section{The Police Data}

The police crime data utilized in this study contained the addresses of all residential burglaries within Zone 7 known to TPD between 19921996, plus the method of entry (e.g., forcible or non-forcible) and point of entry (e.g., window or door) of the offenses. The data also pointed out dates and times of service for residential burglaries known to TPD. These could not be used as dates and times of criminal events, because they more accurately represent when the criminal events were discovered and called in to the police by citizens. Past research (e.g., LeBeau and Coulson, 1996) suggests that calls to police can be used as indicators of when people are home, and thus, can be used as indicators of lifestyles. However, more direct measures of lifestyles were used in this study. 


\section{Hypotheses}

This research tested the following specific hypotheses related to lifestyles:

\section{Hypothesis I:}

Student residents would report less obligatory activities than nonstudent residents;

Hypothesis JI:

Student residents would report less regularity of obligatory activities than non-student residents;

Hypothesis III:

Student residents would report a higher volume of discretionary activities than non-student residents;

Hypothesis JV:

Student residents would report lower periods of total nonoccupancy than non-student residents;

\section{Hypothesis V:}

Student residents would report less regular periods of nonoccupancy than non-student residents;

It was assumed that if these findings were obtained, such lifestyle differences would lead to different volumes and regularity of movement patterns around residences, including pedestrian and automotive traffic. Logically, areas occupied by greater numbers of students should then be characterized by higher levels of irregular routine activities.

It was expected that differential volumes and regularity of routine activities (i.e., pedestrian and automotive traffic) on streets bordering residences would be related to differential rates of residential burglary victimization. This research tested the following specific hypotheses related to routine activities:

Hypothesis VJ:

Volume of traffic would be inversely related to the rate of burglary victimization -- i.e., residences on streets with more traffic would have lower rates of burglary victimization; and, 


\section{Hypothesis VII:}

Regularity of traffic would be positively related to the rate of burglary victimization -- i.e., residences on streets with less regular traffic would have lower rates of burglary victimization.

Since surveillability (i.e., the ability of people to see likely offenders) is inversely related to burglary rates (see Robinson, 1994), higher volumes of people passing by a street segment should be inversely related to burglary rates. Since offenders watch and try to predict residents' schedules, and prefer to burglarize residences whose occupants have predictable schedules (Cromwell, Olson, and Avary, 1991; Tunnell, 1994; Wright and Decker, 1994), the less regular the routine activities around a block, the lower the burglary rate should be.

\section{Design}

This research utilized two distinct methodologies:

1) Self-report measures of lifestyles of different types of residents through a telephone survey; and

2) Actual on-the-site observations of volume and regularity of routine activities (i.e., pedestrian and automotive traffic) on streets bordering residences.

While the former is common in the literature concerning lifestyles, routine activities, and crime (e.g., see Abercrombie et al., 1974; Clark, 1988; Cohen and Cantor, 1981; Cohen and Felson, 1979; Corrado et al., 1980; Felson and Gottfredson, 1984; Godschalk and Godschalk, 1966; Hough, 1987; Illinois Reminiscence Survey, 1979; Kennedy and Forde, 1990; Lasley and Rosenbaum, 1988; Massey, Krohn, and Bonati, 1989; Maxfield, 1987; Miethe, Stafford, and Long, 1987; Moriarty and Williams, 1997; Riley, 1987; Robinson, 1995; Sampson and Wooldredge, 1987; Smith, 1982), the latter has never been utilized in a study of lifestyles and routine activities and crime to the knowledge of the author. This is in large part due to the difficult nature of direct observations, as well as the considerable cost to the researcher both in terms of time and money. Since this study actually measures routine activities of people in time and space, this research may suggest a significant improvement to researchers by suggesting and demonstrating improved measurement of lifestyles and routine activities associated with a particular crime at a particular place. 


\section{TELEPHONE SURVEY}

The limitations of self-report data are well-known and do not need to be readdressed here (e.g., see Robinson, 1997b). When taken as a supplementary source, self-report measures can be very useful. This is especially true, given the limits of our current data for understanding how places relate to criminal events. Rosenbaum and Lavrakas (1995:290-291) pointed out the weaknesses of our present data for fully understanding the significance of "place" for crime. For example, the use of existing police records is inadequate since they "simply do not contain the types of data that are needed to draw a complete picture of the criminological forces at work in specific locations." The National Incidence Based Reporting System (NIBRS) has been developed as a potential replacement for the Uniform Crime Reports partly for this reason. Plus, all the well-known limitations of official police data (e.g., see Robinson, 1994) "mcy lead to biased conclusions about where offenders live, where crimes occur and the nature of criminal events" (Rosenbaum and Lavrakas, 1995:291). Thus, Rosenbaum and Lavrakas (1995:285, 291) advocated using small-scale surveys and interviews as a "complimentary approach" to generate new environmental data to supplement official statistics, and to advance the criminology of place. Specifically, they suggested that researchers should define the social and physical reality of place from the viewpoint of persons who frequent that area (Rosenbaum and Lavrakas, 1995:289), since who would know better about the nature of place-specific features than people who live in an area (e.g., see Moriarty and Williams, 1996). This is the approach followed in this study. Residents of Zone 7 in Tallahassee were asked a series of questions related to their own lifestyles, as well as to the general environmental conditions which surround their residences (e.g., how well they know their neighbors).

\section{Sample}

The telephone survey was conducted on a simple random sample of residents with phones in the area of Zone 7 of Tallahassee, Florida. The sampling frame of telephone numbers of residences in Zone 7 was obtained through the "Phone Disc" CD-Rom program, supplied by Database America. This program contained all listed phone numbers of residences in Tallahassee, Florida, including Zone 7. Other information available through this program included addresses and names of residents in each residence with listed phone numbers. The primary sources from which the sampling frame in the Phone Disc program were built are White Page 
Directories. Directories are compiled on disc by city, street, zip code, and so forth.

The sample was selected by using a Computer Assisted Dialing (CADI) machine. For purposes of maximizing reliability, the author supervised the telephone survey process in order to make certain that questions were being read in their entirety and that surveyors were not taking liberties in clarifying the questions in ways that might influence answers of respondents. Of the 1,328 potential respondents (adults only) who answered the phone, 623 (47\%) agreed to participate in the survey. Of course, the ideal response rate for a telephone survey would be $100 \%$. Response bias may be a concern in this study, because only about half (47\%) of potential respondents participated in the survey. This means there is a possibility that those who responded do not represent the entire population of those potential respondents in Zone 7 of Tallahassee. A follow-up survey of randomly selected non-respondents was an impossibility because the telephone surveys were anonymous in order to minimize risk for the respondents. The presence of this limitation means that caution should be (and will be) taken when making generalizations beyond this sample to larger populations.

\section{Lifestyle Measures}

The self-report measures were compiled from measures used in previous research. In this study, more than one person could not be interviewed per household despite the fact that by only interviewing one persoR "it is possible that a biased within-unit respondent selection procedure would be employed" (Rosenbaum and Lavrakas, 1995:297). Yet, the questions of the phone survey pertained to the lifestyles of all the household members, not just the individual respondent, since burglary is a crime against households and not individuals (Thompson and Fisher, 1996).

Recall that this study defines lifestyles as the activities that people engage in on a daily basis -- it is what people do in time and space. Lifestyles include obligatory activities (e.g., going to work and school) and discretionary activities (e.g., engaging in recreation). The specific measures utilized for obligatory activities included the number of hours per day that respondents spent at school and/or at work. Measures of discretionary activities included the number of times per month that respondents engaged in going shopping, playing sports, going to a bar or club, going to a movie, going out to eat, and going for a walk or drive. Each of these was drawn from the previous literature. Respondents were also asked whether someone was generally home during the day on weekdays in their residences, how often they left their residences for any purpose (to engage 
in obligatory or discretionary activities) and to describe their typical week as either "I do the same things at the same times everyday" or "I do different things at different times everyday." Respondents were also asked how well they knew their neighbors, and about basic demographic variables.

\section{On-Site Observations}

The on-site observations of routine activities were achieved through the use of "electric eye" counters, which were placed at representative locations at various times of day and days of week on Tallahassee streets in residential areas. These devices counted any movement which interrupted the flow of a light beam that was sent and reflected back by a mirror across streets. Streets in Zone 7 of Tallahassee were assigned to one of four categories ("Minor Arterial, Major Collector, Minor Collector, or Local Street") based on advisement from staff of the Tallahassee-Leon County Planning Department (TLCPD). The study used a stratified random sampling design, as streets were first selected and then random segments on those streets were selected for measurement of routine activities (i.e., pedestrian and automotive traffic).

\section{Sample}

The final sample consisted of street segments on 3 major arterials, 3 major collectors, 3 minor collectors, and 4 local streets. Measurements of pedestrian and automotive traffic were taken three days a week at each street location (Wednesday, Thursday, and Sunday), for a total of three onehour periods of time each day (11 a.m. - 12 p.m., 4:30 p.m. - 5:30 p.m., and 10 p.m. - 11 p.m.) in order to enhance the probability that a reasonably representative sample of routine activities (pedestrian and automotive traffic) at each location would be captured for purposes of analysis.

\section{Routine Activity Measures}

Recall that this study defines routine activities as "any recurrent and prevalent activities which provide for basic population and individual needs, whatever their biological or cultural origins . . . including formalized work, leisure, social interaction, learning . . . which occur at home, in jobs away from home, and in other activities away from home" (Cohen and Felson, 1979:593). These routine activities result from peoples' lifestyles -from people engaging in their obligatory and discretionary activities -- and include volumes and regularity of both pedestrian and automotive traffic. 
All measures of routine activities (i.e., pedestrian and automotive traffic) on the thirteen streets were taken during an eight week period in 1997. In order to utilize more valid rates of residential burglary for the thirteen streets, an average rate of residential burglary between the years 1992-1996 was calculated for each street. Measures of routine activities could not be collected by researchers in-between 1992 and 1996; therefore, members of TLCPD were consulted for traffic counts on the thirteen street segments between the years 1992-1996. These routine activities measures from 1992-1996 were then "pooled" together and used to test the relationship between routine activities on street segments between 19921996 and residential burglary rates on the same street segments between 1992-1996. Therefore, the sample size was increased from thirteen street segments to sixty-five street segments, since the author now had routine activities measures for thirteen street segments for each of the five years (1992 to 1996). This increased sample size allowed OLS regression models to be run in order to assess the relationship between volume of routine activities and residential burglary victimization rates. In the regression models, volume of routine activities was operationalized as the total number of automobiles which were counted over each of the measurement periods from 1992-1996. Since 1992-1996 data on pedestrian traffic was not gathered by TLCPD staff, this measure could not be used in regression analysis. Instead, volume of pedestrian traffic was operationalized as the total number of pedestrians which were counted over each of the measurement periods in 1997 only.

The relationship between regularity of routine activities and residential burglary rates could only be assessed using 1997 routine activity data, as well, since the 1992-1996 measures obtained from TLCPD contained no hourly variations, which could have been used to establish the variation of routine activities on street segments. Since this resulted in a sample size of only thirteen street segments, OLS regression could not be run in order to assess this relationship. Instead, Pearson's r2 was used. Regularity of routine activities was operationalized as the variation in pedestrian and automobile traffic counts over each of the measurement periods. Therefore, street segments with high variations in routine activities were considered low in regularity, and street segments with low variations in routine activities were considered high in regularity.

During measurement periods, researchers recorded observations of other place features, which based on the literature, could have had effects on either the level of pedestrian and automotive traffic and/or the burglary rate. The place features that were observed included presence of construction on the street (yes or no), presence of closed lanes of traffic on the street (yes or no), presence of sidewalks (yes or no), indications of neighborhood watch 
in the area (e.g., presence of signs, patrols -- yes or no), indications of heavy security mechanisms on residences on the street (e.g., burglar bars, alarm stickers and signs -- yes or no), indications of incivilities (e.g., presence of graffiti, vacant buildings, garbage -- yes or no), and the general level of surveillability (completely unobstructed, partially obstructed, or completely obstructed by foliage and/or structure). The surveillability categories were established by a panel of judges in the first study by the author (Robinson, 1994; see Robinson, 1997a). These are similar to "control variables" from previous studies, such as that conducted by Roundtree and Land (1996: 159). As it turned out, none of the street segments in the sample was located in an area where construction was taking place, where closed lanes of traffic were located, or where incivilities were present; therefore, these variables were not used for analysis.

\section{FINDINGS}

\section{Telephone Survey}

The majority of the sample of respondents in Zone 7 was made up of college or university students, as $21 \%$ reported being only students $(n=130)$ and another 32\% reported being employed students ( $n=199)$. Another $30 \%$ said they were only employed $(n=185)$, while $17 \%$ reported being neither students nor employees, such as retired citizens, homemakers, disabled citizens, and so forth ( $\mathrm{n}=109)$.

Table I demonstrates that students reported spending less time on average per week engaging in obligatory activities away from home (14.05 credit hours) than employees (40.90 work hours) and employed students (35.20 credit hours and work hours). Of course, by definition, people who are neither students nor employees can have no obligatory activities away from home as they have been operationalized in this study. The differences between the three means (obligatory activities of students, employees, and employed students $)$ is statistically significant $(\mathrm{F}=678.45, \quad \mathrm{p}<0.0001)$. Hypotheses I is supported.

Since out of these three groups, students are the least "obligated" to activities away from their homes, they should logically be expected to engage in more free-time, recreational or 'discretionary' activities. Table 2 shows the mean hours respondents reported engaging in discretionary activities -- i.e., those activities that respondents choose to engage in away from home, either to play sports, go to bars or clubs, go out to movies, go out to eat, go shopping, or go for a walk or drive. 
from home, either to play sports, go to bars or clubs, go out to movies, go out to eat, go shopping, or go for a walk or drive.

Table 1

MEAN HOURS SPENT IN OBLIGATORY ACTIVITIES

(CREDIT HOURS AND/OR WORK HOURS) N=609

$\begin{array}{lll}\text { Main Status } & \text { Mean } & \text { N } \\ \text { Only a Student } & 14.05 \text { (hours) } & 129 \\ \text { Only Employed } & 40.90 & 181 \\ \text { Both } & 32.20 & 190 \\ \text { Neither } & 0 & 109\end{array}$

Table 2 illustrates that students and employed students reported more frequently engaging in sports, going to bars or clubs, going to movies, eating out, and shopping than employees and respondents who reported being neither students nor employees. Yet, students and employed students reported going for walks or drives less frequently than employees and respondents who reported being neither students nor employees. The differences in means for each of these relationships was statistically significant (playing sports -- $\mathrm{F}=1 \mathrm{l} .13, \mathrm{p}<0.0001$; going to bar or club -$\mathrm{F}=21.19, \mathrm{p}<0.001$ : going to a movie $--\mathrm{F}=16.92, \mathrm{p}<0.0001$; going out to eat -- $\mathrm{F}=1 \mathrm{l} .14, \mathrm{p}<0.0001$; going shopping $-\mathrm{F}=4.51, \mathrm{p}<0.004$ : going for a walk or drive -- $\mathrm{F}=7.12, \mathrm{p}<0.0002$ ). Hypotheses III is supported.

The next three tables compare students and employees. Table 3 shows the mean time of day that respondents reported leaving their residences to go to school or work. Table 3 indicates that tle average time of day that students reported leaving tlleir residences for purposes of going to school was 9:59 a.m., while the average time of day that employees reported leaving their residences for purposes of going to work was 8:53 a.m. This difference is statistically significant $(t=-2.97$, d.f. $=265, p<0.002)$. Therefore, students in the sample reported leaving their residences over an hour later, on average, than employees, for purposes of engaging in obligatory activities. Table 3 also demonstrates that $42 \%$ of students reported that the time of day that they left for school varied daily, versus $15 \%$ of employees who indicated that the time of day they left for work varied daily. This provides support for the notion that students' schedules are less regular from day to day than schedules of employees. Hypothesis II is supported. 
Table 2

MEAN MONTHLY TIMES ENGAGED IN DISCRETIONARY ACTIVITIES (AWAY FROM WORK AND/OR SCHOOL)

\begin{tabular}{|c|c|c|}
\hline & Mean & $\mathbf{n}$ \\
\hline \multicolumn{3}{|l|}{ Sports } \\
\hline Only a Student & 8.33 Times & 129 \\
\hline Only Employed & 4.21 & 185 \\
\hline Both & 7.42 & 196 \\
\hline \multirow[t]{2}{*}{ Neither } & 2.90 & 109 \\
\hline & & 619 \\
\hline \multicolumn{3}{|l|}{ Bar/Club } \\
\hline Only a Student & 5.40 & 130 \\
\hline Only Employed & 2.32 & 185 \\
\hline Both & 4.91 & 197 \\
\hline \multirow[t]{2}{*}{ Neither } & 1.01 & 109 \\
\hline & & 621 \\
\hline \multicolumn{3}{|l|}{ Movie } \\
\hline Only a Student & 2.47 & 130 \\
\hline Only Employed & 1.66 & 185 \\
\hline Both & 2.61 & 196 \\
\hline \multirow[t]{2}{*}{ Neither } & 0.72 & 109 \\
\hline & & 620 \\
\hline \multicolumn{3}{|l|}{ Eat Out } \\
\hline Only a Student & 7.18 & 129 \\
\hline Only Employed & 6.97 & 184 \\
\hline Both & 8.25 & 197 \\
\hline \multirow[t]{2}{*}{ Neither } & 3.13 & 109 \\
\hline & & 619 \\
\hline \multicolumn{3}{|l|}{ Shop } \\
\hline Only a Student & 5.55 & 129 \\
\hline Only Employed & 5.04 & 184 \\
\hline Both & 5.81 & 198 \\
\hline \multirow[t]{2}{*}{ Neither } & 3.50 & 109 \\
\hline & & 615 \\
\hline \multicolumn{3}{|l|}{ Walk/Drive } \\
\hline Only a Student & 7.77 & 129 \\
\hline Only Employed & 10.34 & 183 \\
\hline Both & 6.40 & 197 \\
\hline \multirow[t]{2}{*}{ Neither } & 11.41 & 109 \\
\hline & & 618 \\
\hline
\end{tabular}


Table 3

MEAN TIME OF DAY RESPONDENTS LEFT RESIDENCES TO GO TO

SCHOOL OR WORK

\begin{tabular}{l}
\hline $\begin{array}{l}\text { Time of Day } \\
\text { Only a Student } \\
\text { Only Employed } \\
\text { 9:59 a.m.* }\end{array}$ \\
* $42 \%$ a.m. \\
versus 15\% of employees who indicated that the time of day they left for work \\
varied daily.
\end{tabular}

Table 4 shows the mean time of day that respondents reported returning to their residences from school or work. Table 4 indicates that the average time of day that students reported returning to their residences from school was 4:04 p.m., while the average time of day that employees reported returning to their residences from work was 5:21 p.m. This difference is statistically significant $(\mathrm{t}=3.06$, d.f. $=263, \mathrm{p}<0.002)$. Therefore, students in the sample reported returning to their homes over an hour earlier from obligatory activities, on average, than employees. Table 4 also demonstrates that $49 \%$ of students reported that the time of day that they returned from school varied daily, versus $20 \%$ of employees who indicated that the time of day they returned from work varied daily. This provides further support for the notion that students' schedules are less regular from day to day than schedules of employees and for Hypothesis II.

\section{Table 4}

MEAN TIME OF DAY RESPONDENTS RETURNED TO

RESIDENCES FROM SCHOOL OR WORK

Only a Student

Only Employed
Time of Day

4:04 p.m.*

5:21 p.m. n

107

i I I

265

* $49 \%$ of students reported that the time of day they returned from school varied daily, versus $20 \%$ of employees who indicated that the time of day they returned from work varied daily. 
Table 5 shows the average total time of non-occupancy that can be attributed to obligatory activities for students and employees. Table 5 demonstrates that students reported being away for an average of 6 hours, 5 minutes per day, versus 8 hours, 28 minutes per day for employees. This difference is statistically significant $(t=12.49$, d.f. $=259, \mathrm{p}<0.001)$. This means that the students in the sample reported being away from home less hours per day, on average, than employees, for purposes of engaging in obligatory activities. Hypothesis IV is supported.

Tables 3-5 show that among sample respondents: students reported leaving their residence for school later than employees reported leaving their residences for work; students reported returning from school earlier than employees reported returning to their residences from work; and students reported shorter periods of non-occupancy than employees for purposes of engaging in obligatory activities. However, a residence's occupancy involves more than just the occupancy patterns of one resident. The occupancy patterns of other roommates also affect the overall periods of non-occupancy for a residence.

\section{Table 5}

MEAN HOURS OF NON-OCCUPANCY PER DAY FOR RESPONDENTS (AT SCHOOL AND/OR WORK)

\begin{tabular}{lll}
\hline & Hours & $\mathrm{n}$ \\
Only a Student & $6: 05$ (hours) & 103 \\
Only Employed & $8: 28$ & $\mathbf{i ~ I ~ I ~}$ \\
& & 261 \\
\hline
\end{tabular}

Table 6 shows the percentage of respondents who indicated that someone was home on weekdays in their residences during the day. Table 6 illustrates that $75 \%$ of students reported that someone was home during the day in their residences on weekdays, versus 39\% of employees, $64 \%$ of employed students, and $94 \%$ of respondents who reported being neither students nor employees. These differences are statistically significant $\left(\mathrm{V}=0.40 ; \mathrm{x}^{2}=98.23\right.$, d.f. $\left.=3, \mathrm{p}<0.00001\right)$. Therefore, the group least likely to report living in a residence where someone is home during the weekday was the employed group. This finding also supports Hypothesis IV, suggesting that students spend more time at home during the day on weekdays than non-students. 
Table 6

WAS SOMEONE HOME DURING THE DAYTIME ON WEEKDAYS?

\begin{tabular}{lllll}
\hline & Only Student & Only Employed & Both & Neither \\
No & $25 \%$ & $61 \%$ & $36 \%$ & $6 \%$ \\
Yes & $75 \%$ & $39 \%$ & $64 \%$ & $94 \%$ \\
N & 130 & 181 & 195 & 108 \\
\hline
\end{tabular}

Table 7 shows the mean number of times per weekday and weekend that respondents reported leaving their residences for any purpose (e.g., to go to school, to go to work, to shop, or to engage in recreation). Table 7 demonstrates that students (4.50) and employed students (4.04) reported leaving their residences more times on average per weekday than employees (2.83) and those respondents who reported being neither students nor employees ( 1.70). These differences are statistically significant $(\mathrm{F}=23.46, \mathrm{p}<0.0001)$. Table 7 also illustrates that students (3.94) and employed students (3.82) reported leaving their residences more times on average per weekend days than employees (2.64) and those respondents who reported being neither students nor employees (1.77). These differences are statistically significant $(F=17.45, p<0.0001)$. Therefore, students and employed students come and go more frequently from their residences than people who are only employed or who are neither employed nor students. Hypothesis V is supported.

Table 8 shows the percentage of respondents who described their "typical week" as either "I do the same things at the same times everyday" or "I do different things at different times everyday." Table 8 illustrates that $56 \%$ of employees, $48 \%$ of employed students, and $47 \%$ of those respondents who reported being neither students nor employees said that they did the same things at the same times everyday, versus only $35 \%$ of students. These differences are statistically significant $\left(\mathrm{V}=0.11 ; \mathrm{x}^{2}=14.13\right.$. d.f.=6, $\mathrm{p}<0.029)$. The group least likely to report "doing the same things at the same times everyday" were students. This provides further support for the notion that daily schedules for students are less regular than employees, employed students, or people who are neither employed nor students, and for Hypothesis V. 
Table 7

MEAN NUMBER OF TIMES RESPONDENTS LEFT RESIDENCES PER WEEKDAY AND WEEKEND (TO GO TO SCHOOL, WORK, SHOP, OR ENGAGE IN RECREATION)

\begin{tabular}{lll}
\hline & & \\
& Mean Weekday & $\mathrm{n}$ \\
Only a Student & 4.50 times & 126 \\
Only Employed & 2.83 & 179 \\
Both & 4.04 & 190 \\
Neither & 1.70 & 104 \\
& & 599 \\
& & \\
Only a Student & Mean Weekend & $\mathrm{n}$ \\
Only Employed & 3.94 & 126 \\
Both & 2.64 & 175 \\
Neither & 3.82 & 188 \\
& 1.77 & 103 \\
& & 592 \\
\hline
\end{tabular}

Table 8

DESCRIPTION OF TYPICAL WEEK OF RESPONDENTS

Do the Same

Only Student Only Employed Both Neither

Thing

Everyday $\quad 35 \%$

$56 \%$

$48 \% \quad 47 \%$

Do Different

Things

Everyday

$50 \%$

$36 \%$

$39 \% \quad 44 \%$

Neither

$15 \%$

$8 \%$

$1359 \%$

N

130

184

$195 \quad 109$ 


\section{On-Site Observations}

Regression analysis showed that residential street segments with more automotive traffic between 1992-1996 had lower rates of residential burglary victimization between 1992-1996 $\left(\mathrm{R}^{2}=-0.20, \mathrm{p}<0.0002\right)$. That is, streets with higher levels of automotive traffic had lower rates of residential burglary victimization. Hypothesis VI is supported.

The analysis of 1997 routine activities data showed that residential street segments with more pedestrian traffic in 1997 had lower rates of residential burglary victimization between 1992-1996 (Pearson $=s r^{2}=-0.43$, $\mathrm{p}<0.016$ ). That is, streets with higher levels of pedestrian traffic had lower rates of residential burglary victimization. This provides more support for Hypothesis VI. Residential street segments with less regular pedestrian traffic across measurements in 1997 had lower rates of residential burglary victimization between 1992-1996 (Pearson $=s r^{2}=-0.31, p<0.049$ ). That is, streets with greater variation in pedestrian traffic across measurements had lower rates of residential burglary victimization. Hypothesis VII is supported. Residential street segments with less regular automotive traffic across measurements in 1997 also had lower rates of residential burglary victimization (Pearson $=s r^{2}=-0.08, p<0.343$ ). That is, streets with greater variation in automotive traffic across measurements had lower rates of residential burglary victimization, although this relationship was not statistically significant.

None of the other place characteristics, including presence of neighborhood watch, presence of heavy security mechanisms, and level of surveillability to passersby were statistically significantly related to the residential burglary rate. Therefore, the differential rates of burglary on street segments where measurements were taken could not be attributed to any of these factors. They were also not likely attributable to differential levels of social control networks among residents and their neighbors or because of differential levels of living alone. In this study, students and employed students reported lower levels of knowing their neighbors than employees and those respondents who were neither employees nor students. Also, students and employed students were just as likely to report living with others as employees and those respondents who were neither employees nor students. 


\section{CONCLUSION}

This research has suggested and demonstrated improvements in actually measuring the relationship between people's lifestyles, routine activities, and criminal victimization. The author has shown that it is possible to directly measure the routine activities around residences that result from differential lifestyles through direct observations. Routine activities were operationalized as the volume and regularity of pedestrian and automotive traffic on street segments surrounding residential areas. The findings showed that residential burglary rates from 1992-1996 on a sample of randomly selected street segments in Tallahassee, Florida, were inversely related to the volume of automotive traffic on those streets from 1992-1996 and the volume of pedestrian traffic on those streets in 1997. The findings also showed that residential burglary rates from 1992-1996 on the street segments were positively related to the regularity of pedestrian and automotive traffic across measurements taken in 1997, although the findings for automotive traffic were not statistically significant.

The findings of this research also demonstrated that students reported engaging in less obligatory activities per day than non-students, but reported engaging in higher levels of discretionary activities per day than non-student groups. Further, the findings illustrated that students reported coming and going from their residences more times per day than nonstudents, and that their daily activities were more sporadic or less regular than daily activities of non-students. The result is that students in the sample reported both lower total periods of non-occupancy and less regular periods of non-occupancy than non-student groups. The higher volumes of irregular pedestrian and automotive traffic which result from such sporadic lifestyles could be why lower rates of residential burglary are found at student apartment complexes in Zone 7 of Tallahassee, Florida. No other place characteristic which was measured was found to be statistically significantly related to the rate of residential burglary on the street segments. Logically, when several hundred students are engaging in their sporadic daily lifestyles, routine activities around their residences will be higher in volume and more irregular than in other areas inhabited primarily by persons who are full-time employees and whose daily activities are more regular, patterned, or predictable. Conditions of high volumes of irregular routine activities do not seem to be favorable ones for the commission of residential burglary, at least in this study. Clearly, more research is warranted in order to establish the generalizability of these findings. Should other research find that sporadic or unpredictable lifestyles and routine activities be related to lower burglary rates, crime prevention 
policies could be derived which would entail making it more difficult for burglars to predict periods of non-occupancy.

\section{REFERENCES}

Abercrombie, Nicholas, Cullen, Ian, Godson, Vida, Major, Sandra \& Timson, Lesley. (1974). The university in an urban environment: A study Of activity patterns from a planning viewpoint London, England: Heinemann.

Akers, Ronald. (1994). Criminological theory: Introduction and evaluation. Los Angeles: Roxbury.

Bennett, Richard. (1991). "Routine activities: A cross-national assessment of a criminological perspective." Social Forces 70(1), 147-63.

Chapin, F. Stuart, Jr. (1974). Human activitv patterns in the citv: Things People do in time and space. New York: John Wiley \& Sons.

Clark, David. (1988). An analysis of guardian effectiveness in the prevention of residential burglary. Ph.D. Dissertation. State University of New York at Albany.

Clarke, Ronald \& Felson, Marcus. (1993). Routine activity and rational choice. London, England: Transaction.

Cohen, Lawrence \& Cantor, David. (1981). "Residential burglary in the United states: Lifestyle and demographic factors associated with the probability of victimization." Journal of Research in Crime and Delinquency 18(1), 113-27.

Cohen, Lawrence \& Felson, Marcus. (1979). "Social change and crime rate trends: A routine activity approach." American Sociological Review 44, 588-608.

Cohen, Lawrence, Felson, Marcus \& Land, Kenneth. (1980). "property Crime rates in the united states: A macrodynamic analysis, 1947-1977; with ex ante forecasts for the mid-1980's." American Journal of Sociology 86, 90-118. 
Cohen, Lawrence, Kluegel, James \& Land, Kenneth. (1981). "social Inequality and predatory criminal victimization: An exposition and a test of a formal theory." American Sociological Review 46, 505-524.

Corrado, R., Roesch, R., Glackman, W., Evans, J. \& Ledger, G. (1980). "Lifestyles and personal victimization: A test of the model with Canadian survey data." Journal of Crime and Justice 3, 129-139.

Cromwell, Paul, Olson, James \& Avary, D.W. (1991). Breaking and entering: An ethnographic analysis of burglary. Newbury Park, Calif.: Sage.

Eck, John. (1994). Drug markets and drug places: A case-control study of The spatial structure of illicit drug dealing. Ph.D. Dissertation, University of Maryland.

Eck, John \& Weisburd, David. (1995). Crime and place. Monsey, NY: Criminal Justice Press.

Fattah, Ezzat. (1993). The rational choice/opportunity perspectives as a Vehicle for integrating criminological and victimological theories. In Ronald Clarke \& Marcus Felson (Eds.), Routine activity and rational choice. Advances in criminological theory, vol. 5. New Brunswick, NJ: Transaction Publishers.

Felson, Marcus. (1983). Ecology of crime. In S. Kadish (Ed.), Encyclopedia of crime and justice.

Felson, Marcus. (1986). Linking the criminal choices, routine activities, informal control, and criminal outcomes. In Derrick Comish \& Ronald Clarke (Eds.), The reasoning criminal: Rational choice perspectives on offending. New York: Springer-Verlag.

Felson, Marcus. (1987). "Routine activities and crime prevention in the developing metropolis." Criminology 25(4), 911-931.

Felson, Marcus. (1994). Crime and everyday life: Insights and implications for society. Thousand Oaks, Calif.: Pine Forge Press.

Felson, Marcus. (1995). Those who discourage crime. In John Eck \& David Weisburd (Eds.), Crime and place. Monsey, NY: Criminal Justice Press. 
Felson, Marcus \& Gottfredson, Michael. (1984). "Social indicators of Adolescent activities near peers and parents." Journal of Marriage and the Family 46, 709-714.

Garofalo, James. (1987). Reassessing the lifestyle model of criminal victimization. In Michael Gottfredson \& Travis Hirschi (Eds.), Positive criminology. Newbury Park, Calif.: Sage.

Godschalk, David \& Godschalk, Lallie. (1966). A study of household Activity patterns in Titusville, Florida. Tallahassee, Flor.: The Florida State University, Department of Urban and Regional Planning and Urban Research Center, Institute for Social Research.

Goldstein, Arnold. (1994). The ecology of aggression. New York: Plenum Press.

Gottfredson, Michael. (1984). Victims of crime: The dimensions of risk. Home Office Research Study No. 81, Her Majesty's Stationary Office, London.

Hindelang, Michael, Gottfredson, Michael \& Garofalo, James. (1978). Victims of personal crime: An empirical foundation for a theory of personal victimization. Cambridge, Mass.: Ballinger.

Hough, Mike. (1987). "Offenders' choice of targets: Findings from victim surveys." Journal of Quantitative Criminology_3(4), 355-370.

Illinois Criminal Justice Information Authority. (1979). Spatial and Temporal analysis of crime: Users manual/technical manual. Chicago, Illin.: Illinois Criminal Justice Information Authority, State of Illinois.

Kennedy, Leslie \& Baron, Stephen. (1993). "Routine activities and a Subculture of violence: A study of violence on the street." Journal of Research in Crime and Delinquency 30(1), 88-112.

Kennedy, Leslie \& Forde, David. (1990). "Risky lifestyles and dangerous results: Routine activities and exposure to crime." Sociology and Social Research: An International Journal 74(4), 208-211. 
Lasley, James \& Rosenbaum, Jill. (1988). "Routine activities and multiple personal victimization." Sociology and Social Research: An International Journal 73(1), 47-50.

LeBeau, James \& Corcoran, W. (1990). "Changes in calls for police Service with changes in routine activities and the arrival and passage of weather fronts." Journal of Quantitative Criminology 6, 269-291.

LeBeau, James \& Coulson, Richard. (1996). "Routine activities and the Spatial temporal variation of calls for police service: the experience of opposites on the quality of life spectrum." Police Studies 19(4), 1-14.

Massey, James, Krohn, Marvin \& Bonati, Lisa. (1989). "Property crime and the routine activities of individuals." Journal of Research in Crime and Delinquency 26(4), 378-400.

Maxfield, Michael. (1987). "Lifestyle and routine activity theories of crime: Empirical studies of victimization, delinquency, and offender decision-making." Journal of Quantitative Criminology 3(4), 275-282.

Miethe, Terance, Stafford, Mark \& Long, J. Scott. (1987). "social Differentiation in criminal victimization: A test of routine activities I lifestyle theories." American Sociological Review 52, 184-194.

Moriarty, Laura \& Williams, James. (1996). "Examining the relationship between routine activities theory and social disorganization: An analysis of property crime victimization." American Journal of Criminal Justice 21(1), 43-59.

Riley, David. (1987). "Time and crime: The link between teenager lifestyle And delinquency." Journal of Quantitative Criminology 3(4), 339-354.

Robinson, Matthew. (1994). Environmental characteristics associated with residential burglaries of private apartment complexes predominantly occupied by university students. Master's Thesis: Florida State University School of Criminology and Criminal Justice.

Robinson, Matthew. (1995). "Once bitten, but not twice bitten: Student apartment burglary 'cool spots'." Paper presented to the annual conference of the Southern Criminal Justice Association.

Robinson, Matthew. (1996). "The relationship of student activity patterns 
To select types of victimization on- and off-campus." Paper presented to the annual meeting of the American Society of Criminology.

Robinson, Matthew (1997a). "Burglary re-victimization: The time period of heightened risk." British Journal of Criminology 38(1), 76-85.

Robinson, Matthew. (1997b). Lifestyles, routine activities, and residential burglary victimization. Ph.D. Dissertation: Florida State University School of Criminology and Criminal Justice.

Robinson, Matthew \& Christine Robinson. (1997). "environmental characteristics associated with residential burglary. "Environment and Behavior 29(5), 657-675.

Roncek, Dennis \& Maier, Pamela. (1991). "Bars, blocks, and crimes revisited: Linking the theory of routine activities to the empiricism of 'hot spots."' Criminology 29(4), 725-753.

Rosenbaum, Dennis \& Lavrakas, Paul. (1995). Self-reports about place: The application of survey and interview methods to the study of small areas. In John Eck \& David Weisburd (Eds.), Crime and place. Monsey, NY: Criminal Justice Press.

Roundtree, Pamela \& Land, Kenneth. (1996). "Burglary victimization, perceptions of crime risk, and routine activities: A multilevel analysis across seattle neighborhoods and census tracts." Journal of Research in Crime and Delinquency 33(2), 147-180.

Sampson, Robert \& Wooldredge, John. (1987). "Linking the micro- and macro- level dimensions of lifestyle-routine activity and opportunity models of predatory victimization." Journal of Quantitative Criminology 3(4), 371-

393.

Sherman, Lawrence. (1995). Hot spots of crime and criminal careers of place. In John Eck \& David Weisburd (Eds.), Crime and place. Monsey, NY: Criminal Justice Press.

Sherman, Lawrence, Gartin, Patrick \& Buerger, Michael. (1989). "hot spots of predatory crime: Routine activities and the criminology of place." Criminology 27(1), 27-55.

Smith, S. (1982). "Victimization in the inner city." British Journal of 
Criminology 22(2), 386-402.

Thompson, Carol \& Fisher, Bonnie. (1996). "Predicting household Victimization utilizing a multi-level routine activity approach." Journal of Crime and Justice 19(2), 49-66.

Tunnell, K. (1994). Choosing crime: The criminal calculus of property offenders. Chicago, Illinois: Nelson-Hall Publishers.

Weisburd, David. (1997). Reorienting crime prevention research and policy: from the causes of criminality to the context of crime. National Institute of Justice Research Report. Washington, DC: U.S. Department of Justice.

Wright, Richard \& Decker, Scott. (1994). Burglars on the job: Streetlife And residential break-ins. Boston, Mass.: Northeastern University Press. 